\title{
Neutral Endopeptidase Inhibitors Potentiate Substance P- and Capsaicin-induced Cough in Awake Guinea Pigs
}

\author{
H. Kohrogi, P. D. Graf, K. Sekizawa, D. B. Borson, and J. A. Nadel \\ Cardiovascular Research Institute, University of California, San Francisco, California 94143
}

\begin{abstract}
To study the roles of substance $P$ and endogenous neutral endopeptidase in mediating cough, we measured cough responses in awake guinea pigs in response to exogenous substance $P$ and capsaicin aerosols in the presence and absence of the neutral endopeptidase inhibitors leucine-thiorphan and phosphoramidon. Substance $P$ stimulated cough in very low concentrations $\left(10^{-17}-10^{-16} \mathrm{M}\right)$. In a second study where the investigator did not know whether substance $P$ or diluent alone was aerosolized, substance $P\left(10^{-16} \mathrm{M}\right)$ caused cough. Leucine-thiorphan $\left(10^{-5} \mathrm{M}\right)$ and phosphoramidon $\left(10^{-5} \mathrm{M}\right)$ potentiated substance P-induced cough; NEP inhibitors also potentiated capsaicininduced cough significantly. These findings suggest that substance $P$ is a potent stimulator of cough responses, that capsaicin-induced cough is mediated by substance $P$ or another similar neuropeptide, and that cough responses are modulated by endogenous neutral endopeptidase.
\end{abstract}

\section{Introduction}

Cough is an important respiratory defense mechanism $(1,2)$, and it is one of the most important symptoms of respiratory disease. Sensory nerve endings in the airways are believed to transmit cough signals from the airways to the central nervous system via the vagus nerves (3-7). Substance $P(S P)^{1}$-like immunoreactivity has been found in the airways of several species, including humans and guinea pigs $(8-10)$. Substance $P$ is released from sensory nerves in the airways by capsaicin and by electrical stimulation (12). Substance $P$ has been shown to have many pro-inflammatory actions in the lungs, e.g., bronchoconstriction (12-15), increases in vascular permeability (11), and increases in secretion from glands (16-18). Because capsaicin releases SP from sensory nerves, it has pro-inflammatory actions in the lungs similar to those of SP (11), and it causes cough in humans (19) and in guinea pigs (7). However, the effect of SP on cough responses is not known. Because SP is known to stimulate abdominal visceral sensory nerves in

A preliminary report was published in abstract form in 1988. (FASEB J. 2:1383a.)

Address reprint requests to Dr. Nadel, Cardiovascular Research Institute, Box 0130, University of California, San Francisco, CA 94143-0130.

Received for publication 7 December 1987 and in revised form 7 April 1988.

1. Abbreviations used in this paper: 1-thiorphan, leucine thiorphan; NEP, neutral endopeptidase; SP, substance P.

J. Clin. Invest.

(c) The American Society for Clinical Investigation, Inc.

$0021-9738 / 88 / 12 / 2063 / 06 \$ 2.00$

Volume 82, December 1988, 2063-2068 cats (20), it is possible that SP itself might directly stimulate cough responses.

The actions of SP in the airways are modified by peptidases, especially neutral endopeptidase (NEP) (also called enkephalinase, membrane metalloendopeptidase, E.C. 3.4.24.11). Neutral endopeptidase activity exists in airways and in the vagus nerves of ferrets (21), and in the tracheas and bronchi of guinea pigs (22). Immunoreactive NEP has been visualized in the vagus nerves using a polyclonal antibody (unpublished results). In the airways, NEP inhibitors potentiate the effects of SP on secretion from glands (18), on smooth muscle contraction, and on cholinergic neurotransmission (15), suggesting that NEP present in the airways normally cleaves SP to inactive metabolites and thereby limits its actions.

In this study, we attempted to determine whether exogenously applied or endogenously released SP stimulates cough responses and whether the NEP inhibitors leucine-thiorphan (l-thiorphan), an analogue of thiorphan (23), or phosphoramidon, by preventing the cleavage of SP by NEP, might exaggerate the effects of SP on cough responses. To stimulate the release of endogenous SP, we used capsaicin (the active component of red pepper), an agent known to stimulate the neural release of SP (24).

\section{Methods}

Measurement of cough responses. Guinea pigs were chosen because they are known to cough in response to irritants (7). We used 87 guinea pigs (male Hartley, 450-550 g in weight). Guinea pigs were treated according to procedures of The Committee on Animal Care at The University of California, San Francisco. Because the cough reflex is reduced by anesthesia as are other vagal reflexes (25), we studied cough responses in awake animals. Each guinea pig was placed in a horizontally fixed 1-liter glass jar and allowed to relax. Two holes (5-mm diam) were made in the cap of the jar near the nose of the guinea pig. One hole was connected via a tube to a source of constant flow of 0.6 liters/min. This served to provide fresh air to the inside of the jar. To expose the guinea pig to aerosols, we switched the airflow source to provide airflow from an ultrasonic nebulizer (DeVilbiss 25), which produces particles of a mean mass diameter of $7.6 \pm 2.6 \mu \mathrm{m}$ (geometric standard deviation). The output of the nebulizer was $0.2 \mathrm{ml} / \mathrm{min}$. The second hole in the cap of the jar was connected to a pneumotachograph (Fleisch 00), which was attached to a differential strain gauge (PM5; Statham Instruments, Oxnard, CA), and airflow was recorded on a polygraph (Grass 5D; Grass Instrument Co., Inc., Quincy, MA). Cough was detected as transient changes in airflow: a rapid inspiration followed by rapid expiration (see Fig. 1). Previous studies have used measurements of airflow to assess frequency of cough (26). Because motion of the guinea pig in the jar also produced changes in recorded flow, we continuously monitored this activity visually and disregarded motion-induced changes in airflow. After each study, the jar, tubing, and nebulizer were washed in hot water, followed by solutions of $\mathrm{NaOH}$ ( $\mathrm{pH} \mathrm{11}$ ), 100\% ethanol, and water to ensure that drugs that had deposited on their walls were removed.

In preliminary studies, animals were observed for $5 \mathrm{~min}$ in the 


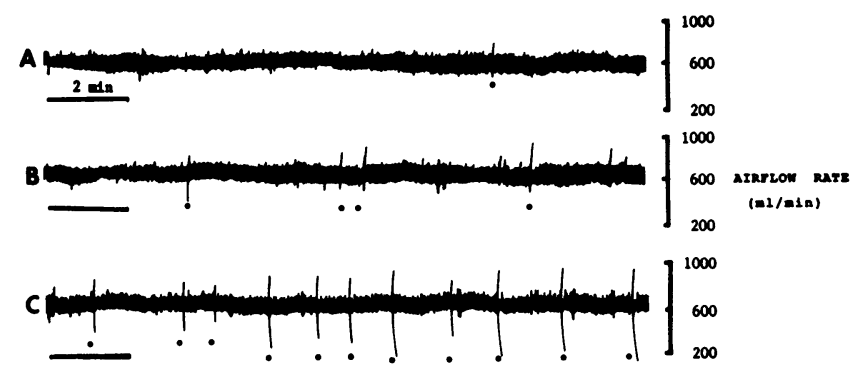

Figure 1. Record of cough responses to aerosols ( $2 \mathrm{~min}$; horizontal bars) of saline $(A)$, substance $\mathrm{P}(\mathrm{SP})\left(10^{-17} \mathrm{M} ; B\right)$, and $\mathrm{SP}\left(10^{-17} \mathrm{M}\right)$ after leucine-thiorphan $\left(10^{-5} \mathrm{M}, 5 \mathrm{~min} ; C\right)$ in a guinea pig (as described in Methods). Vertical bars show the airflow rate through the pneumotachograph (in milliliters per min). Each cough is indicated by the symbol (0). The number of coughs was increased slightly by exposure to SP aerosol but was increased markedly by SP after leucine-thiorphan.

absence of stimulation, during which time the number of coughs were counted. Of the 11 animals studied, only 2 coughed during this period. The average number of coughs was $0.18 \pm 0.12$ in $5 \mathrm{~min}$, a number not statistically different from zero. Next, to determine whether saline or the vehicle for l-thiorphan caused cough or potentiated saline-induced cough, we first exposed animals to ethanol ( $1 \%$ in saline for $5 \mathrm{~min}$ ), and then, at 15-min intervals, we exposed them to saline for $2 \mathrm{~min}$.

Substance P-induced cough. In the next series of experiments, we selected guinea pigs that coughed less than three times during a 5-min exposure to an aerosol of saline $(0.9 \% \mathrm{NaCl})$ and $0.1 \%$ ethanol (the vehicle for l-thiorphan). The guinea pigs were then allowed to rest for $15 \mathrm{~min}$ before further study. To evaluate the effects of SP on cough responses, we exposed guinea pigs to SP for $2 \mathrm{~min}$ and then observed them for an additional $13 \mathrm{~min}$, and we counted the total number of coughs during the entire 15-min period. Preliminary studies showed that a single exposure to saline aerosols induced $2.1 \pm 2.0$ coughs in 15 $\min$ (mean $\pm \mathrm{SD} ; 5$ guinea pigs), so we defined the threshold for SP-induced cough to be five or more coughs during the 15 -min period. Guinea pigs were exposed to increasing concentrations of SP starting at $10^{-18} \mathrm{M}$, until significant cough responses were obtained. At higher concentrations (e.g., $10^{-14} \mathrm{M}$ ), the responses were large and not reproducible. Furthermore, because subsequent exposure to saline-stimulated cough in guinea pigs that had large cough responses to SP, we discontinued exposure after determining the threshold of the response.

Because very low concentrations of SP were sufficient to produce cough, we performed an additional group of experiments in which one observer prepared the drugs. A second observer, who did not know the contents of the aerosol generator or the sequence of the exposures, monitored the responses. In these experiments, we exposed 10 guinea pigs to $0.1 \%$ ethanol and saline vehicle for $5 \mathrm{~min}$ and waited for an additional $15 \mathrm{~min}$. Then, after the baseline response to saline was determined, we exposed five guinea pigs to $S P\left(10^{-16} \mathrm{M}\right)$ and five other guinea pigs to the SP vehicle alone (acetic acid, $10^{-14} \mathrm{~N}$ ) for $2 \mathrm{~min}$ and observed them for $13 \mathrm{~min}$. We counted the number of coughs during this 15 -min period. Because it is possible that the acetic acid $(0.1 \mathrm{~N})$ used to dissolve the SP might stimulate cough, we performed additional experiments in which we dissolved the SP in saline rather than acetic acid and delivered first saline and then SP $\left(10^{-16} \mathrm{M}\right.$; each exposure, $2 \mathrm{~min}$ ) and monitored cough for an additional $13 \mathrm{~min}$.

Effects of neutral endopeptidase inhibitors. To determine whether endogenous NEP modulates SP-induced cough, $4 \mathrm{~h}$ after the first exposure to SP, we repeated the SP exposure in five guinea pigs $15 \mathrm{~min}$ after exposing them to aerosols of l-thiorphan $\left(10^{-5} \mathrm{M}, 5 \mathrm{~min}\right)$. Preliminary studies showed that 1-thiorphan alone did not stimulate cough more than saline ( $1.3 \pm 0.6$ vs. $1.2 \pm 0.2$ coughs in $5 \mathrm{~min})$ and did not potentiate saline-induced cough compared to the effects of its vehicle ( $0.1 \%$ ethanol; $3.3 \pm 0.8$ vs. $2.2 \pm 0.5$ coughs in $15 \mathrm{~min}$ ). After l-thior- phan treatment, exposures to SP were begun at concentrations 1,000 fold below the threshold concentration of SP alone in the same guinea pig. In five additional animals, we repeated the SP exposure $15 \mathrm{~min}$ after exposing the animal to aerosols of the vehicle for 1-thiorphan ( $0.1 \%$ ethanol and saline, $5 \mathrm{~min}$ ). Because l-thiorphan inhibits airway kininase II in addition to NEP (27), it is possible that the effects of 1-thiorphan were mediated by inhibition of kininase II. Therefore, we studied the effects of phosphoramidon, an NEP inhibitor with minimal effects on airway kininase II (27). Animals received aerosols of either saline or phosphoramidon $\left(10^{-5} \mathrm{M}, 5 \mathrm{~min}\right)$, followed $10 \mathrm{~min}$ later by either saline or SP $\left(10^{-16} \mathrm{M}, 2 \mathrm{~min}\right)$.

Capsaicin-induced cough. To study capsaicin-induced cough, we avoided the problem of tachyphylaxis by dividing the experiments into two groups:

We exposed three guinea pigs first to l-thiorphan $\left(10^{-5} \mathrm{M}\right)$ for $5 \mathrm{~min}$ and waited for an additional $15 \mathrm{~min}$. Then, after the baseline response to saline was determined, we exposed them to capsaicin for $2 \mathrm{~min}$ at a concentration $\left(10^{-18} \mathrm{M}\right)$ that is near threshold and observed them for an additional $13 \mathrm{~min}$, during which time we counted the total number of coughs. 1 wk later, as a control, we exposed the same guinea pigs to $0.1 \%$ the ethanol and saline vehicle (instead of l-thiorphan) for $5 \mathrm{~min}$ and waited for $15 \mathrm{~min}$. Then, after the baseline response to saline exposure was determined, we exposed them to capsaicin $\left(10^{-18} \mathrm{M}\right.$, 2 min).

We exposed the other three guinea pigs first to aerosols of the $0.1 \%$ ethanol and saline vehicle, followed by saline and then capsaicin. A week later, we reexposed this group of animals first to l-thiorphan, then to saline, and finally to capsaicin.

In another study, we determined the effects in different animals either of saline (vehicle for phosphoramidon) or of phosphoramidon $\left(10^{-5} \mathrm{M}, 5 \mathrm{~min}\right.$ each) on cough induced by capsaicin $\left(10^{-17} \mathrm{M}, 2 \mathrm{~min}\right)$ in each of five guinea pigs.

We attempted to determine whether SP receptor antagonists altered SP- or capsaicin-induced cough responses, but preliminary studies showed that [D-Pro $\left.{ }^{2}, \mathrm{D}-\mathrm{Trp}^{7,9}\right]-\mathrm{SP}(n=3)$ or [D-Arg ${ }^{1}, \mathrm{D}-\mathrm{Pro}^{2}, \mathrm{D}-$ $\operatorname{Trp}^{7,9}$, Leu $\left.^{11}\right]$-SP $(n=5)$ alone stimulated cough in concentrations ranging from $10^{-16}$ to $10^{-7} \mathrm{M}$, thus making this strategy unsuitable for further study. To compare the SP- or capsaicin-induced cough responses to those induced by a known stimulant of cough, we exposed two additional guinea pigs to histamine ( 2 min, starting at $\left.10^{-10} \mathrm{M}\right)$, in the absence and presence of 1-thiorphan.

Preparation of drugs. For most of the studies, SP (Peninsula Labs, Belmont, $\mathrm{CA}$ ) was dissolved in $0.1 \mathrm{~N}$ acetic acid to give a stock solution of $10^{-3} \mathrm{M}$ that was stored at $-25^{\circ} \mathrm{C}$. 1-Thiorphan (a gift from E. R. Squibb Pharmaceuticals, Inc., Princeton, NJ) was dissolved in $100 \%$ ethanol, and capsaicin (Sigma Chemical Co., St. Louis, MO) was dissolved in $10 \%$ ethanol and $10 \%$ Tween 80 in $0.9 \%$ saline to give stock solutions of $10^{-2} \mathrm{M}$ that were stored at $4^{\circ} \mathrm{C}$. These stock solutions were diluted in $0.9 \%$ saline as necessary for each experiment. Histamine (Sigma Chemical Co.) was dissolved in $0.9 \%$ saline.

Data analysis. Unless otherwise stated, data are expressed as the number of coughs (mean $\pm \mathrm{SE}$ ) during the observation period (15 min). Cough responses were compared by one-way analysis of variance and Newman-Keuls test for multiple comparisons. Significance was accepted at $P<0.05$.

\section{Results}

In the absence of any aerosol, the average number of coughs in a 5-min observation period was $0.18 \pm 0.12$, a number not statistically different from zero. Neither ethanol nor any of three exposures to saline caused cough $(2.3 \pm 1.4,1.7 \pm 0.9,3.0 \pm 1.2$, and 3.7 \pm 0.9 , respectively; $n=3$ each).

Substance P-induced cough. Substance $P$ increased the number of coughs in a dose-dependent fashion. During the first exposure to SP in acetic acid, the threshold concentration 


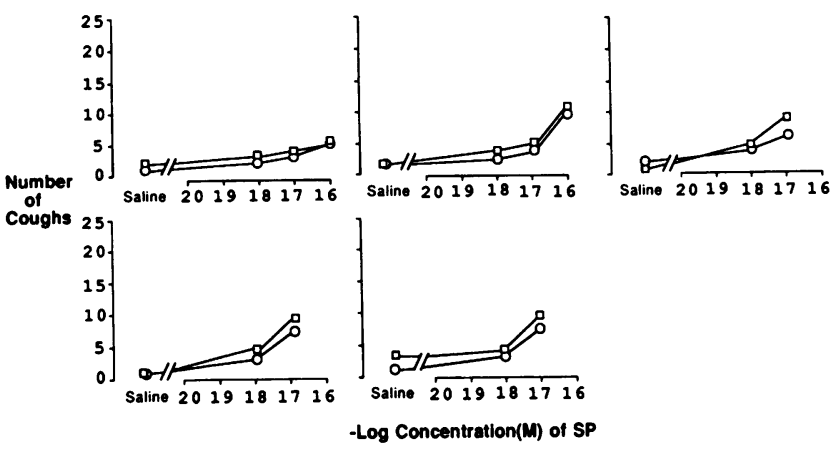

Figure 2. Reproducibility of the effects of saline and substance P (SP) on cough responses in five awake guinea pigs. Data are expressed as the total number of coughs observed during a 2-min exposure and the subsequent 13-min period after the end of exposure to saline or to SP. Each panel shows data for one guinea pig. The threshold for SP-induced cough is between $10^{-17}$ and $10^{-16} \mathrm{M}$ for each animal. The second study $(\square)$ in each animal was performed $4 \mathrm{~h}$ after the first study (O) and showed that the second responses to SP were slightly greater than the first.

was $10^{-17}$ or $10^{-16} \mathrm{M}$ for SP (Fig. 2). $4 \mathrm{~h}$ later, when we repeated the study, the number of SP-induced coughs was slightly greater at the threshold concentration $(7.0 \pm 0.8$ compared to $8.6 \pm 1.0 ; P<0.05$ ), although there were no significant increases in the number of coughs upon reexposure to saline. Although there was an increase in the number of coughs at the threshold concentration of SP in four of five guinea pigs, the threshold concentration did not decrease more than one log unit.

In the group of experiments in which the observer was not familiar with the contents of the aerosol generator or the sequence of the exposures, $\operatorname{SP}\left(10^{-16} \mathrm{M}\right)$ stimulated cough significantly more than saline did $(9.2 \pm 1.7$ vs. $3.6 \pm 0.7 ; P<0.05, n$ $=5)$. However, the vehicle of SP $(0.1 \mathrm{~N}$ acetic acid diluted to $10^{-14} \mathrm{M}$ ) alone did not stimulate cough more than saline did (3.4 \pm 0.8 vs. $2.4 \pm 1.0 ; P>0.05, n=5)$. In the absence of added acetic acid, SP stimulated cough significantly more than saline

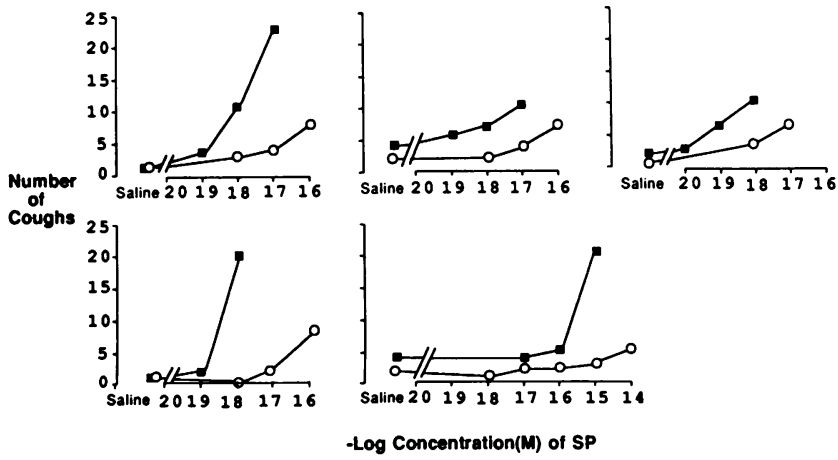

Figure 3. Effects of leucine-thiorphan on saline and substance $\mathbf{P}$ (SP)-induced cough in five awake guinea pigs. Data are expressed as the total number of coughs in a 15 -min observation period. Each panel shows data for one guinea pig. Open circles show responses to SP alone. Closed squares show responses to SP after exposure to leucine-thiorphan ( $\left.10^{-5} \mathrm{M}, 5 \mathrm{~min}\right)$. In each guinea pig, leucine-thiorphan shifted the concentration-response curve to SP to lower concentrations and increased the number of coughs in response to SP. did (6.0 \pm 0.5 vs. $1.2 \pm 0.5$ coughs in $15 \mathrm{~min}$, respectively; $P$ $<0.001, n=5$ ).

Leucine-thiorphan potentiated SP-induced cough (Fig. 3). After treatment with 1-thiorphan, the dose-response curves were shifted to lower concentrations of SP by at least two log units in each of five guinea pigs, and the number of coughs increased strikingly in three of five guinea pigs. There were no significant increases in cough upon reexposure to saline. Although phosphoramidon alone did not stimulate cough more than saline did $(1.4 \pm 0.9$ vs. $1.2 \pm 0.2$ coughs in $5 \mathrm{~min})$, it potentiated the response to SP $\left(10^{-16} \mathrm{M}\right)$ significantly compared to the response to SP alone ( $14.0 \pm 4.1$ vs. $5.2 \pm 0.6$ coughs in 15 min, respectively; $P<0.025, n=5$ each). Additionally, phosphoramidon potentiated the responses to saline and to acetic acid $\left(10^{-14} \mathrm{M}\right)$ slightly compared to the response to saline alone (3.8 \pm 1.1 and $4.4 \pm 1.7$ vs. $2.0 \pm 0.6$, respectively), but the increases were not significant ( $n=5$ each).

Leucine-thiorphan did not potentiate histamine-induced cough. In each of two guinea pigs, the threshold concentrations of histamine were $10^{-8}$ and $10^{-7} \mathrm{M}$, respectively. After treatment with l-thiorphan, the dose-response curves were not different.

Capsaicin-induced cough. Capsaicin alone caused cough in a concentration-dependent fashion, with responses to $10^{-18}$ and $10^{-17} \mathrm{M}$ of $4.3 \pm 0.7$ and $5.8 \pm 1.3$ coughs in $15 \mathrm{~min}$, respectively $(P<0.05, n=5$ each). Leucine-thiorphan itself did not cause more cough than did its vehicle $(3.6 \pm 1.1$ vs. $3.2 \pm 1.3, P$ $>0.05 ; n=6$ ), and l-thiorphan did not potentiate saline-induced cough more than did its vehicle $(3.3 \pm 0.9$ vs. $3.8 \pm 0.8, P$ $>0.05, n=6$ ). However, 1-thiorphan increased cough responses induced by capsaicin $\left(10^{-18} \mathrm{M}\right)$ significantly compared to the response to capsaicin after $0.1 \%$ ethanol (vehicle for 1-thiorphan) (7.8 \pm 0.7 vs. $4.3 \pm 0.7 ; P<0.01, n=6)$. Additionally, phosphoramidon potentiated the number of coughs in response to $10^{-17} \mathrm{M}$ capsaicin compared to capsaicin alone (11.6 \pm 1.7 vs. $5.8 \pm 1.3$, respectively; $P<0.05, n=5$ each).

\section{Discussion}

This study in awake guinea pig demonstrated three findings. First, exogenous SP causes cough in very low concentrations $\left(10^{-18}-10^{-16} \mathrm{M}\right)$. Second, endogenously released SP causes cough. Third, endogenous NEP modulates cough responses to exogenously delivered SP and to endogenously released neuropeptides (presumably tachykinins).

Substance P-induced cough. The high sensitivity of guinea pigs to SP demonstrates that this peptide is an extremely potent stimulant to cough. The response was not due to the presence of acetic acid because acetic acid alone did not stimulate cough, and SP dissolved in saline caused cough to the same degree as SP dissolved in acetic acid. Because SP is diluted in the fluid that coats the airway surface, the actual concentration of SP in the airway fluid is probably less than that delivered in the aerosols. Additionally, because NEP is present in the airway epithelial cells and nerves (21), the concentration of SP reaching the sensory nerve receptors is probably even lower. The effect of SP is probably specific because the response is dose dependent. In addition to its direct effects to stimulate cough, SP appears to alter the threshold of subsequent responses to SP and thereby to increase the number of coughs in response to a threshold concentration. Although the 
mechanism is not certain, it is possible that SP, by inducing inflammation in the airway tissue (11), changes the responsiveness to SP. Alternatively, because SP stimulates sensory nerves, SP might stimulate the release of additional SP from the airway sensory nerves, increasing the local concentration of the peptide in the airways and thereby increasing the magnitude of the effects of subsequent doses of SP.

The mechanism by which SP stimulates cough is not known, but several possibilities exist. First, SP may stimulate the sensory nerve endings in the airways of guinea pigs, as it does in the gastrointestinal tract of cats, where it stimulates abdominal visceral afferent nerves (20). Second, SP may stimulate cough indirectly by releasing histamine from mast cells (28). Third, mechanical stimulation of sensory nerves may be caused by mucus secretion (16-18) or by bronchoconstriction (12-15) in response to SP. However, the low concentrations of SP sufficient to cause cough are far lower than those required to release histamine from mast cells or to stimulate mucus secretion or bronchoconstriction. Thus, these mechanisms are unlikely to be responsible for mediating cough responses. Therefore, the most likely mechanism of action of SP is via stimulation of sensory nerves directly. At a concentration of $10^{-17} \mathrm{M}$, the number of molecules aerosolized in $2 \mathrm{~min}$ is $\sim 2,400$. Because most of the aerosol generated is not inhaled, only a few hundred molecules of SP are likely to reach the airways. Thus, a very small number of SP molecules represents a stimulus sufficient to elicit the cough response. This extreme sensitivity is similar to the sensitivities of insect behavioral or electrophysiological responses to peripherally applied pheromones (29) in which only a few molecules can be a sufficient stimulus. In insects, the very high sensitivity may result from preferential adsorption of the stimulus molecules to tissues near sensory receptors or to summation of inputs from many sensory nerves to more central neural centers. Thus, neurophysiological studies of single receptors demonstrated that up to 100 times higher concentrations of stimulant may be required to elicit responses from a given nerve than behavioral responses (30).

The site of action of SP in the airways may be in the nose, the pharynx, the trachea, or in the lower airways. The particle size $(7.6 \mu \mathrm{m})$ is sufficiently large to be deposited primarily in the upper airways, structures innervated by the 5 th, 9 th, and 10th cranial nerves (trigeminal, glossopharyngeal, and vagal, respectively). Receptors in these locations can mediate the common chemical sense (e.g., 31), known to be sensitive to irritants such as formaldehyde, ozone, amyl alcohol, and capsaicin, with a threshold of trigeminal receptors to amyl alcohol of 300 parts per trillion in air. This is of similar magnitude to the threshold for histamine-induced cough $\left(10^{-8}-10^{-7} \mathrm{M}\right)$, but is substantially higher than that for SP. Thus, SP appears to be one of the most potent known stimuli for chemically sensitive reflexes in mammals.

The cough reflex is also extremely sensitive to capsaicin; only a few molecules are needed to elicit a response. The action of capsaicin is probably mediated via the release of SP, known to be present in nerves in the vagus (32), because NEP inhibition potentiated the response, suggesting that endogenously released peptides cleaved by NEP were responsible. In the spinal cord, stimulation of sensory nerves by capsaicin releases SP (24), and in the airway, capsaicin causes bronchoconstriction and increases in vascular permeability, effects that are abolished by SP receptor antagonists (11). We were unable to confirm this possibility by using SP receptor antagonists, because the antagonists themselves stimulated cough. Finally, because pretreatment with capsaicin depletes tachykinins from sensory nerves $(33,34)$ and prevents airway responses to vagal nerve stimulation (34) and to irritant stimuli (12), these studies suggest that cough responses elicited by capsaicin are mediated by endogenously released tachykinins.

Previous studies have shown that many biochemical agents can induce cough responses. These include histamine $(35,36)$, bradykinin (37), prostaglandins $E_{1}, E_{2}, F_{2 \alpha}(38)$, and $D_{2}(39)$. The mechanism by which histamine and prostaglandin $F_{2 \alpha}$ stimulate cough is believed to be via stimulation of both irritant receptors (myelinated sensory fibers) and bronchial $\mathrm{C}$ fibers (unmyelinated fibers) $(5,6,40,41)$. Histamine-induced cough is reduced by beta adrenergic agonists, suggesting that cough responses are in part mediated via bronchoconstriction (36). Bradykinin and prostaglandin $E_{2}$ are believed to cause cough by their known actions to stimulate bronchial $\mathrm{C}$ fibers $(5,42)$. However, because the threshold of cough induced by SP was found to be substantially lower $\left(10^{-17}-10^{-16} \mathrm{M}\right)$ than that induced by histamine $\left(10^{-8}\right.$ and $\left.10^{-7} \mathrm{M}\right)$, SP is a more potent stimulant of sensory nerves than histamine or other mediators.

Role of endogenous NEP in modulating tachykinin-induced cough. In this study, the NEP inhibitors l-thiorphan and phosphoramidon potentiated the SP- and capsaicin-induced cough responses. This potentiation was not due to the effects of the NEP inhibitors, because alone they did not stimulate cough and because they did not potentiate saline-induced cough. The most likely explanation for these findings is that exogenously applied or endogenously released SP is cleaved in guinea pig airways by endogenous NEP, thereby reducing the magnitude of the effects of the peptide. NEP is a membrane-bound peptidase that was initially found in the kidney (43) and later identified in the brain (44). Subsequently, the enzymes from the two sources were shown to be identical (45-47). Although no functional roles for NEP have been described in the kidney, this enzyme modulates the effects of opioid peptides in the brain $(23,48)$. NEP exists in many peripheral tissues including the lungs of humans (49), rats (50), and pigs (51), as well as in the airways and vagus nerves of ferrets $(15,21)$, and in the airways of guinea pigs (22). NEP cleaves SP in several positions. For example, its cleavage in the $9-10$ position results in the production of $\mathrm{SP}_{1-9}(52)$, which we have previously shown to be ineffective in stimulating airway gland and smooth muscle responses $(15,18)$. Kinetic studies have demonstrated that SP is a good substrate for NEP (52).

In the present study, l-thiorphan and phosphoramidon also potentiated capsaicin-induced cough. Because these cough responses, as well as bronchoconstrictor responses to capsaicin (22), are potentiated by NEP inhibitors, NEP is probably located near the sites of release and action of SP in the airways (e.g., sensory nerves). Thus, the present data suggests that endogenous SP or another peptide cleaved by NEP is the mediator of capsaicin-induced cough responses.

We speculate that one of the mechanisms by which cough responses are produced is that irritants stimulate sensory nerves in the airways which, in turn, release an endogenous peptide, possibly SP or another tachykinin, which stimulates cough. By degrading the released peptides, endogenous NEP could modulate these responses. 


\section{Acknowledgments}

We thank Beth Cost, Patty Snell, and Nancy Williams for manuscript preparation.

Supported in part by National Institutes of Health Program Project grant HL-24136. Dr. Borson is the recipient of National Institutes of Health First Award HL-38947.

\section{References}

1. Widdicombe, J. G. 1977. Respiratory reflexes and defense. In Respiratory Defense Mechanism. Marcel Dekker, Inc., New York. 593-630.

2. Banner, A. S. 1986. Cough: physiology, evaluation, and treatment. Lung. 164:79-92.

3. Nadel, J. A., and J. G. Widdicombe. 1963. Reflex control of airway size. Ann. NY Acad. Sci. 109:712-723.

4. Widdicombe, J. G. 1954. Receptors in the trachea and bronchi of the cat. J. Physiol. (Lond.). 123:71-104.

5. Coleridge, H. M., J. C. G. Coleridge, K. H. Ginzel, D. G. Baker, R. B. Banzett, and M. A. Morrison. 1976. Stimulation of "irritant" receptors and afferent $\mathrm{C}$-fibers in the lungs by prostaglandins. Nature (Lond.). 264:451-453.

6. Coleridge, H. M., and J. C. G. Coleridge. 1977. Impulse activity in afferent vagal C-fibers with endings in the intrapulmonary airways of dogs. Respir. Physiol. 29:125-142.

7. Forsberg, K., and J.-A. Karlsson. 1986. Cough induced by stimulation of capsaicin-sensitive sensory neurons in conscious guinea-pigs. Acta Physiol. Scand. 128:319-320.

8. Ghatei, M. A., M. N. Sheppard, D. J. O’Shaughnessy, T. E. Adrian, G. P. McGregor, J. M. Polak, and S. R. Bloom. 1982. Regulatory peptides in the mammalian respiratory tract. Endocrinology. 111:1248-1254.

9. Lundberg, J. M., T. Hokfelt, C.-R. Martling, A. Saria, and C. Cuello. 1984. Substance P-immunoreactive sensory nerves in the lower respiratory tract of various mammals including man. Cell Tissue Res. 235:251-261.

10. Hua, X.-Y., E. Theodorsson-Norheim, E. Brodin, J. M. Lundberg, and T. Hokfelt. 1985. Multiple tachykinins (neurokinin A, neuropeptide $K$ and substance $P$ ) in capsaicin-sensitive sensory neurons in the guinea-pig. Regu. Peptdes. 13:1-19.

11. Lundberg, J. M., A. Saria, E. Brodin, S. Rosell, and K. Folkers. 1983. A substance $P$ antagonist inhibits vagally induced increase in vascular permeability and bronchial smooth muscle contraction in the guinea pig. Proc. Natl. Acad. Sci. USA. 80:1120-1124.

12. Lundberg, J. M., and A. Saria. 1983. Capsaicin-induced desensitization of airway mucosa to cigarette smoke, mechanical and chemical irritants. Nature (Lond.). 302:251-253.

13. Lundberg, J. M., C.-R. Martling, and A. Saria. 1983. Substance $\mathrm{P}$ and capsaicin-induced contraction of human bronchi. Acta Physiol. Scand. 119:49-53.

14. Grunstein, M. M., D. T. Tanaka, and J. S. Grunstein. 1984. Mechanism of substance P-induced bronchoconstriction in maturing rabbit. J. Appl. Physiol. 57:1238-1246.

15. Sekizawa, K., J. Tamaoki, J. A. Nadel, and D. B. Borson. 1987. Enkephalinase inhibitor potentiates substance P- and electrically-induced contraction in ferret trachea. J. Appl. Physiol. 63:1401-1405.

16. Baker, A. P., L. M. Hillegass, D. A. Holden, and W. J. Smith. 1977. Effect of kallidin, substance $P$ and other basic polypeptides on the production of respiratory macromolecules. Am. Rev. Respir. Dis. 115:811-817.

17. Gashi, A. A., D. B. Borson, W. E. Finkbeiner, J. A. Nadel, and C. B. Basbaum. 1986. Neuropeptides degranulate serous cells of ferret tracheal glands. Am. J. Physiol. 251:C223-C229.

18. Borson, D. B., R. Corrales, S. Varsano, M. Gold, N. Viro, G. Caughey, J. Ramachandran, and J. A. Nadel. 1987. Enkephalinase inhibitors potentiate substance P-induced secretion of ${ }^{35} \mathrm{SO}_{4}$-macromolecules from ferret trachea. Exp. Lung Res. 12:21-36.

19. Collier, J. G., and R. W. Fuller. 1984. Capsaicin inhalation in man and the effects of sodium cromoglycate. Br. J. Pharmacol. 81:113-117.

20. Lew, W. Y. W., and J. C. Longhurst. 1986. Substance P, 5-hydroxytryptamine, and bradykinin stimulate abdominal visceral afferents. Am. J. Physiol. 250:R465-R473.

21. Borson, D. B., B. Malfroy, M. Gold, J. Ramachandran, and J. A. Nadel. 1986. Tachykinins inhibit enkephalinase activity from tracheas and lungs of ferrets. Physiologist. 29:174.

22. Sheppard, D., J. E. Thompson, L. Scypinski, D. Dusser, J. A. Nadel, and D. B. Borson. Toluene diisocyanate increases airway responsiveness to substance $\mathrm{P}$ and decreases airway enkephalinase. $J$. Clin. Invest.

23. Roques, B. P., M. C. Fournie-Zaluski, E. Soroca, J. M. Lecomte, B. Malfroy, C. Llorens, and J.-C. Schwartz. 1980. The enkephalinase inhibitor thiorphan shows antinociceptive activity in mice. $\mathrm{Na}$ ture (Lond.). 288:286-288.

24. Gamse, R., A. Molnar, and F. Lembeck. 1979. Substance $P$ release from spinal cord slices by capsaicin. Life Sci. 25:629-636.

25. Holtzman, M. J., H. L. Hahn, K. Sasaki, B.-E. Skoogh, P. D. Graf, L. M. Fabbri, and J. A. Nadel. 1982. Selective effect of general anesthetics on reflex bronchoconstrictor responses in dogs. J. Appl. Physiol. 53:126-133.

26. Hanacek, J., A. Davies, and J. G. Widdicombe. 1984. Influence of lung stretch receptors on the cough reflex in rabbits. Respiration. 45:161-168.

27. Dusser, D. J., J. A. Nadel, K. Sekizawa, P. D. Graf, and D. B. Borson. 1988. Neutral endopeptidase and angiotensin converting enzyme inhibitors potentiate kinin-induced contraction of ferret trachea. J. Pharmacol. Exp. Ther. 244:531-536.

28. Foreman, J. C., C. C. Jordan, P. Oehme, and H. Renner. 1983 Structure-activity relationships for some substance P-related peptides that cause wheal and flare reactions in human skin. J. Physiol. (Lond.). 335:449-465.

29. Kaissling, K.-E. 1971. Insect olfaction. In Handbook of Sensory Physiology. Springer Verlag, Berlin. 351-431.

30. Boeckh, J., and V. Boeckh. 1979. Threshold and odor specificity of pheromone-sensitive neurons in the deuterocerebrum of Antheraea pernyi and A. polyphemus (Saturnidae). J. Comp. Physiol. 132:235-242.

31. Silver, W. L. 1987. The common chemical sense. In Neurobiology of Taste and Smell. John Wiley and Sons, New York. 65-87.

32. Lundberg, J. M., E. Brodin, and A. Saria. 1983. Effects and distribution of vagal capsaicin-sensitive substance $P$ neurons with special reference to the trachea and lungs. Acta Physiol. Scand. 119:243252.

33. Jancso, G., E. Kiraly, and A. Jancso-Gabor. 1977. Pharmacologically induced selective degeneration of chemosensitive primary sensory neurons. Nature (Lond.). 270:741-743.

34. Lundberg, J. M., and A. Saria. 1982. Capsaicin-sensitive vagal neurons involved in control of vascular permeability in rat trachea. Acta Physiol. Scand. 115:521-523.

35. Simonsson, B. G., F. M. Jacobs, and J. A. Nadel. 1967. Role of autonomic nervous system and the cough reflex in the increased responsiveness of airways in patients with obstructive airway disease. $J$. Clin. Invest. 46:1812-1818.

36. Chausow, A. M., and A. S. Banner. 1983. Comparison of the tussive effects of histamine and methacholine in humans. J. Appl. Physiol. 55:541-546.

37. Fuller, R. W., C. M. S. Dixon, F. M. C. Cuss, and P. J. Barnes. 1987. Bradykinin-induced bronchoconstriction in humans: mode of action. Am. Rev. Respir. Dis. 135:176-180.

38. Smith, A. P., M. F. Cuthbert, and L. S. Dunlop. 1975. Effects of inhaled prostaglandins $E_{1}, E_{2}$ and $F_{2 \alpha}$ on the airway resistance of healthy and asthmatic man. Clin. Sci. Mol. Med. 48:421-430.

39. Fuller, R. W., C. M. S. Dixon, C. T. Dollery, and P. J. Barnes. 
1986. Prostaglandin $D_{2}$ potentiates airway responsiveness to histamine and methacholine. Am. Rev. Respir. Dis. 133:252-254.

40. Mills, J. E., H. Sellick, and J. G. Widdicombe. 1969. Activity of lung irritant receptors in pulmonary microembolism, anaphylaxis and drug-induced bronchoconstrictions. J. Physiol. (Lond.). 203:337-357.

41. Boushey, H. A., P. S. Richardson, J. G. Widdicombe, and J. C. M. Wise. 1974. The response of laryngeal afferent fibers to mechanical and chemical stimuli. J. Physiol. (Lond.). 240:153-175.

42. Kaufman, M. P., H. M. Coleridge, J. C. G. Coleridge, and D. G. Baker. 1980. Bradykinin stimulates afferent vagal C-fibers in intrapulmonary airways in dogs. J. Appl. Physiol. 48:511-517.

43. Kerr, M. A., and A. J. Kenny. 1974. The purification and specificity of a neutral endopeptidase from rabbit kidney brush border. Biochem. J. 137:477-488.

44. Malfroy, B., J. P. Swerts, A. Guyon, B. P. Roques, and J.-C. Schwartz. 1978. High affinity enkephalin degrading peptidase in mouse brain and its enhanced activity following morphine. Nature (Lond.). 276:523-526.

45. Almenoff, J., S. Wilk, and M. Orlowski. 1981. Membrane bound pituitary metalloendopeptidase: apparent identity to enkephalinase. Biochem. Biophys. Res. Commun. 102:206-214.

46. Malfroy, B., and J.-C. Schwartz. 1982. Properties of enkepha- linase from rat kidney: comparison of dipeptidyl carboxypeptidase and endopeptidase activities. Biochem. Biophys. Res. Commun. 106:276285.

47. Fulcher, I. S., R. Matsas, A. J. Turner, and A. J. Kenny. 1982. Kidney neutral endopeptidase and the hydrolysis of enkephalin by synaptic membranes show similar sensitivity to inhibitors. Biochem. $J$. 203:519-522.

48. Schwartz, J.-C., B. Malfroy, and S. De La Baum. 1981. Mini review. Biological inactivation of enkephalins and the role of enkephalin-dipeptidyl-carboxypeptidase ("enkephalinase") as neuropeptidase. Life Sci. 29:1715-1740.

49. Johnson, A. R., J. Ashton, W. W. Schulz, and E. G. Erdos. 1985. Neutral metalloendopeptidase in human lung tissue and cultured cells. Am. Rev. Respir. Dis. 132:564-568.

50. Llorens, C., and J.-C. Schwartz. 1981. Enkephalinase activity in rat peripheral organs. Eur. J. Pharmacol. 69:113-116.

51. Kenny, A. J., M. A. Bowes, N. S. Gee, and R. Matsas. 1985. Endopeptidase-24.11: a cell-surface enzyme for metabolizing regulatory peptides. Biochem. Soc. Trans. 13:293-295.

52. Turner, A. J., R. Matsas, and A. J. Kenny. 1985. Commentary. Are there neuropeptide-specific peptidases? Biochem. Pharmacol. 34:1347-1356. 